are usually executed by others. Gropius was another architect who did not draw, but in his case the resulting buildings are more variable in character and quality, depending on those with whom he was collaborating. Aalto's scepticism of 'teamwork' would seem justified.

But in most instances, we can point to sketches or doodles by the 'named' architects, and follow the way in which an initial idea is developed and emerges in the built project. Frequently, a powerful design idea is maintained only by a process of eliminating those contradictions that threaten to dilute it. Structural disciplines, servicing requirements and, of course, budgetary constraints all conspire to muddy the elegant conceptual notion. In the case of Aalto's architecture, not only did his initial sketches apparently carry sufficient slack to allow for most of these constraints to be absorbed, but his design philosophy allowed pragmatic variation to affect, and in some instances actually enhance, the form of the buildings. I found an anecdote in Ex Intimo told by Jaakko Kontio, who worked in Aalto's office from 1954 to 1960 , particularly telling:

Whateverblunder you made at work, he never put your back up against the wall like Allu Blomstedt or others did. He always found a solution! And they were brilliant. In the House of Culture when a big sanitary pipe came through in the corner of the concert hall, he solved it so that the spot became the most photographed detail of the whole building!

One can hardly imagine such a tale coming out of the office of Mies van der Rohe, for example. Aalto himself mentioned the 'methodical accommodation to circumstance' of the varied Karelian buildings that he admired so much, and the ability to accommodate the unexpected is one of the benefits of a fluid and inclusive formal vocabulary. Charitableness to the errors of the staff is also easier when 'blunders' can turn out to be beneficial.

If these are advantages of Aalto's style of atelier, what are the disadvantages? Some would presumably find the seamless transition between office and house (in Tiilimäki), and even summer house at Munkkiniemi, to be suffocating. They would rather work in one kind of place and be at home in another. When the staff are also the family, relationships that go wrong can be exceptionally painful.

But to be reminded, in our current less than ideal world, of a form of practice where small groups were responsible under a charismatic architect of unique formal mastery, for buildings of such power and resonance, is a definite privilege.

NICK RAY Cambridge

Nick Ray is Director of NRAP Architects, Cambridge, Reader Emeritus in Architecture and Fellow of Jesus College, Cambridge

\section{A place beyond where we are}

As one who writes and practises in the north of Scotland, I very much enjoyed Laura Hourston Hanks' Island Identities: The Pier Arts Centre, Orkney (arq, 14.3, pp. 222-36). The author writes eloquently about Reiach and Hall Architects' elegant and well-crafted Pier Arts Centre. I would like to take up two themes from the paper: the first about how we imagine and use a sense of north as inspiration; and then to reflect on whether Stromness's singularity limits what we can learn and apply in developing architectural narratives in remote locations

How we describe an architecture bound up in a sense of the north is well described by Hourston Hanks as a critical preoccupation of the Arts Centre's architect and is rightly unfurled as both a sensory phenomenon and as a means of defining a condition of distinctiveness and separation. Peter Davidson's book The Idea of North resonates with the architect Neil Gillespie's praise for the sculptural qualities of a low northern light as critical in situating architecture in high latitudes. There is, however, a restlessness that lies with this, as if always looking to the horizon for an ever more pristine rendering of a cool utopia. Materialising the north is a fragile pursuit, and is quite elusive in lower latitudes. However, the Orkneys with their pared landscapes and pristine light are a delightful reality in which the architect can seek inspiration.

In Scotland, many look to Scandinavian experiences, where the experiential north seems so much more woven into a culture that encompasses the art of Eilif Peterssen and Harald Sohlberg to luxuriating in long nights of Summer with Monika. In our devolutionary culture, there is tacit encouragement to look across the North Sea rather than over the border to define our architecture.
Politically it showed itself as an aspiration to ascend to an 'arc of prosperity' across the northern periphery until our age of insolvency revealed it to be illusory. For Scotland, an idea of north therefore might describe searching for a place beyond where we are. It differs from the Scandinavian experience where it is a concept embedded in its culture. Orkney in its own way wishes clear blue water from the mainland. An affinity towards Scandinavia is perhaps rooted more in forging a distinctive identity from Scotland's Central Belt than a seamless celebration of a common history.

The distinctive sense of light and space is an integral part of defining an architecture founded in the high latitudes of the Orkneys and indeed has that abstract quality that fits well within a well-versed canon of Critical Regionalism. I would argue, however, that there are limits to this beyond which we simply appropriate cultural narratives without enough critical discernment.

I would pose a question of how much can we take from the paper to help us intervene meaningfully in the Scots landscape? There is a sense that the Arts Centre lies in a gentle but persuasive straitjacket, in a context with little latitude to strike out on its own. The distinctive massing of the waterside makes the 'second shed' almost the missing part of an intricate spatial jigsaw. The design follows through with a reinterpretation of the existing harbourside buildings. So much of it is therefore about Stromness. The collection that lies within the building is staged within a more internationalist 'white cube'. It could be considered that rather than the building occupying a 'position as mediator between past and present', it is one that accommodates two quite distinctive worlds. A globalised consensus as to how art should be staged contrasts with the imperatives laid down by cultural and physical context. The Arts Centre is an interesting reversal of Bagsvaerd church as it is described by Kenneth Frampton in Towards a Critical Regionalism: Six Points for an Architecture of Resistance. The church's generic exterior and specific interior are inverted in Stromness. The interior of the second shed is internationalised contrasting strongly with the contextual certainties that mould the building's exterior form.

Many architects in Scotland grapple with what it means to build within rural landscapes. There is a 

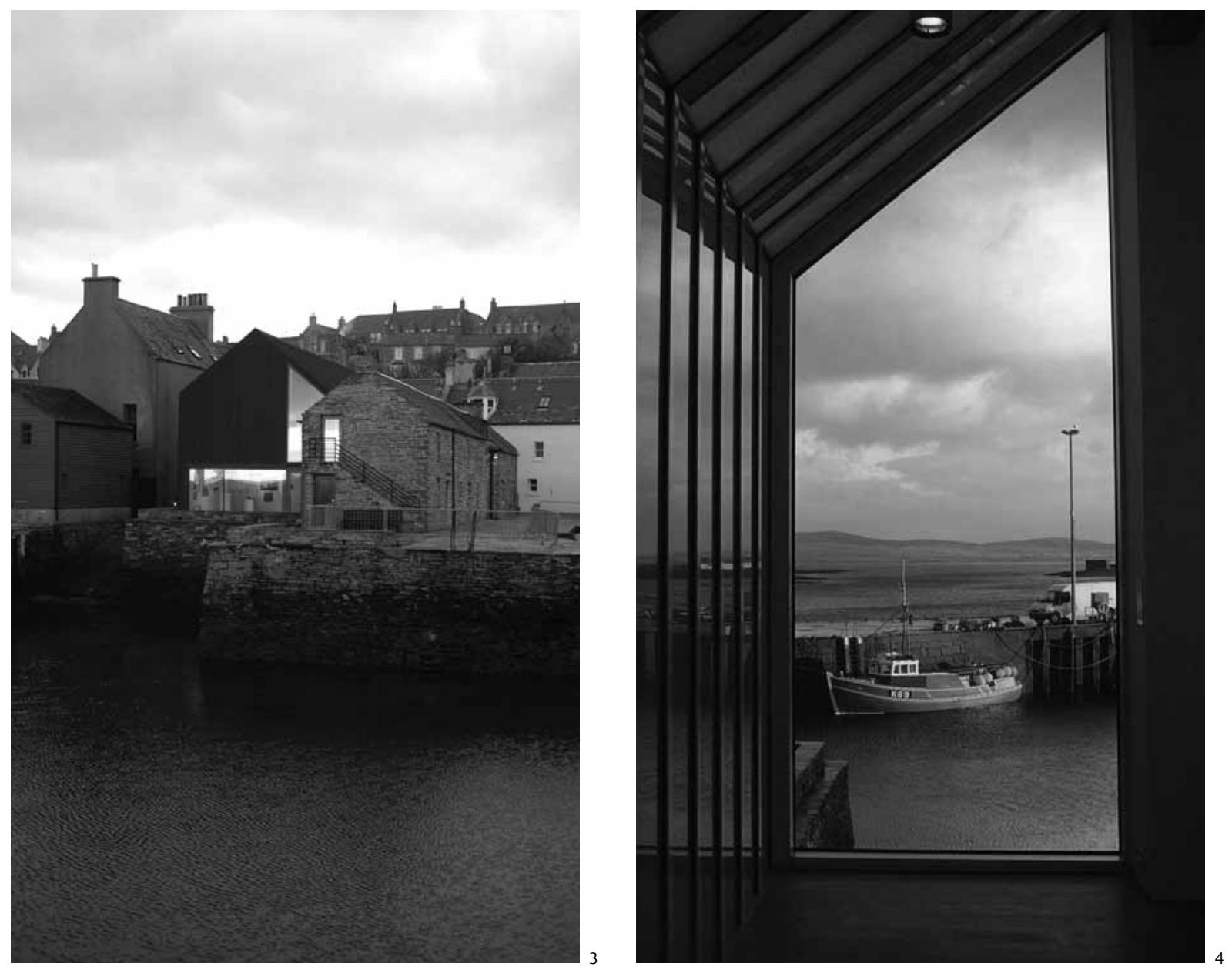

3-4 The 'craft and sensitivities' of Reiach and Hall's Pier Arts Centre,

Stromness, in 'the most secure of contexts'

paradox that, given its remoteness, Stromness is almost unbearably intense in its urbanism. The article describes the building as having a dialogue between a charged, intensely local context and an outward looking internationalism. It is, all told, very much a utopian manifestation of the north. We have in Hourston Hanks' paper a lucid, sensitive exposition of Reiach and Hall's great skill in crafting a fine building. Where I think we need to look further is what can be learnt to design elsewhere in a Scots landscape less blessed with such strong cultural and spatial cues. The recent competition for $\mathrm{V} \& \mathrm{~A}$ Dundee shows how, when cut loose from its host city, the iconic architecture of the 'destination' building takes hold. The unpacking of the Pier Arts Centre illuminates craft and sensitivity, but is tested in the most secure of contexts.

\section{JOHN BRENNAN} Edinburgh

John Brennan is a practising architect and Senior Lecturer at the Edinburgh School of Architecture and Landscape Architecture

\section{Broadening entry to the profession}

Architecture is not an invisible profession. Conversely, unlike other construction-related professional areas, architecture is very visible in the minds of the public. It is often mentioned in the same breath as law and medicine as one of the elite professional areas that a highflying student might aspire to join. Consequently the need to raise the profile of the profession in the minds of students to encourage applicants to architecture courses does not seem to apply when considering whether there is value in developing an A-level in Architecture as described by Robert Atkinson (arq, 14.3, pp 267-76).

This A-level course has been running at Richmond upon Thames College since 2001 and has attracted over a hundred students in the last three academic years. It is clearly a popular course, but is it valuable? Atkinson puts forward three main points to support the value of this A-level, but in my view one significant point that will emerge from this discussion is missing from his supporting argument.

Atkinson's first point is that the A-level in Architecture provides an appropriate qualification for students wishing to enter an architecture course at a UK university and enables students to prepare a portfolio of work to present at interviews. The cost of organising interviews in terms of staff time and the pressure on universities to cut costs especially in relation to what are regarded as expensive courses to run means that a large percentage of universities do not call students to interview. Reliance on A-level predictions and final achievement is consequently very strong. In consequence it is significant to look at the way in which universities regard different A-levels. Atkinson relies on the lack of evidence to support the contention that an Architecture A-level will not be as highly regarded as more traditional academic subjects. Bath University's list of subjects that are seen as 'less effective preparation' (LEPs) for the study of Architecture, is cited by Atkinson as evidence that the 